\title{
Tensile Behaviour of Fabric Reinforced Laminates and Plies
}

\begin{abstract}
ANA CAPATINA, VASILE BRIA, MARINA BUNEA, IULIAN-GABRIEL BIRSAN*
Dunarea de J os University, Research and Development Centre for Thermoset Matrix Composites,47 Domneasca Str., 800008, Galati, Romania

The present paper is concerning to an empirical analysis of tensile properties of plies and laminates formed with an epoxy matrix and with various carbon fiber fabrics. The analysis was started with the aim of finding some correlations between the elastic parameters of plies and elastic parameters of laminates when fabrics are used as reinforcements. Six different carbon fiber fabrics were used to analyze the plies and laminates mechanical parameters. The epoxy system Epiphen RE-4020-DE4020 was used in both cases as matrix. The mechanical response to tensile test was analyzed for above mentioned materials and the results had been compared with values obtained by application of various purposed models.
\end{abstract}

Keywords: fabric reinforced composites, polymer matrix composites, tensile tests

It is well known the fact that, for some specific applications, the fabrics made of various types of fibers, are used as reinforcements replacing the use of individual tows of fibers. The high-technology is using even individual fibers to reinforce various materials but for medium applications the tows of fibers are used leading to various geometrical distributions of reinforcement with effects on the composites mechanical properties. In the case of thermoplastic matrix composites the problem was solved with the prepregs and the forming of composite was ensured by increasing the temperature of a pre-defined stack of prepregs under controlled pressure conditions. In the case of thermoset polymers -which are relative insensitive to the temperature value variations -it is very difficult to ensure the spatial regulated distribution of reinforcement tows. There are some solutions even for these polymers but the composite forming is conditioned by the presence of an adhesive between the independent prepregs causing difficulties regarding the material behavior due to the presence of another interphase (the one between adhesive and polymer) even when the adhesive and the matrix belong to the same class of polymers. The use of prepregs is expensive while the use of the classic method of wet layup is cheap and offers more opportunities of intervention in the attempt of final properties design especially when the pre-polymer is presented in liquid phase.

The use of fabrics is ensuring the spatial distribution of fibers yarns and an increased degree of sinuosity of the formed composite but it is involving some reduction of mechanical parameters of the final composite material. The use of fabrics is more and more recognized as a solution to obtain more performant materials even the modeling becomes more complicated and therefore the capacity to predict the final properties is diminished [1-3]. In this regard it is easily to notice that many theoretical studies concern with the 3D woven composites [4-8] as a facile solution to solve the design problem of the final properties of composites. As well as in the case of the 2D woven composites [9-11] the problem solution has to be sought, in our opinion, by taking into account the fact that each phase immersed into a matrix leads to matrix defects with effects on matrix properties. Using regulated distributed fibers or fabrics the defects are regularly distributed inside the matrix (atmacroscopic scale -matrixtows interphase or at microscopic scale matrix-fibers interphase) so the modelling problem concern with an analysis of defects presence inside the matrix. There are, of course, many attempts of using FEM to model the properties of a composite reinforced with fabrics and all of these attempts are based on an elementary cell. The problem with this cell is that it has to be homogenous and isotropic (or, at least orthotropic) while the most cases it is difficult to get the homogenization especially because it is practically impossible to describe the change of tows responses at passages above and under other tows (warp and weft) inside the polymer matrix [12-15].

First approaches regarding the mechanical response of fabric reinforced polymer composites were taking into account the waviness of fabrics as a parameter to describe the lowered values of elastic parameters or the hypothesis that a fabric might be described as a superposition of two orthotropic plies rotated at $90^{\circ}$ and with some geometric corrections [16-19]. Last approaches are using the observation that, generally, when a fabric reinforced laminate is formed there appears differences between the ply thickness and laminate thickness namely the thickness of the laminate is lower than the ply thickness multiplied by number of plies. This effect is denoted as nesting effect in latest studies [20-24] and represents, in fact, a displacement of adjacent reinforcement layers such as each one will occupy the relief of the other leading to unexpected mechanical behavior at micro-level with averaged macro-level effects.

At least, the description of a fabric reinforced polymer matrix composite has to take into account the fact that it is almost impossible to know the real distribution of polymer inside the composite and it is almost obvious that the main failure modes of such composite are determined by the matrix failure [25-30]. In our opinion it would be appropriate to correct mathematical models of fabric reinforced laminates with some statistical analysis. Of course, the above presented are just a part of modelling attempts and, as any model, they are perfectible taking into account other hypothesis or reinterpreting some conditions [31-34].

Many studies are carried out on both theoretical and empirical paths with components of computing but, generally, their common feature is that they take into account a regulated distribution of reinforcement and matrix parts. A visual inspection of fabrics prior to their immersion into the matrix shows small defects of the yarns and these small variations away from uniformity are generating unexpected macroscopic mechanical 
responses. More than that, it is obvious that, depending on yarn dimensions it is very possible that the matrix do not penetrate to the middle of the yarn causing mechanical misbehavior but in this case the discussion has to be extended to the effect of forming technique [35-39].

The below presented study is a pure empirical one and it was developed trying to better understand the tensile behavior of fabric reinforced plies and eventually to identify the change of this mechanical behavior when the ply is placed inside a fabric reinforced laminate polymer matrix material. Of course there are many differences between forming techniques depending on the type of the polymer and there exist studies regarding the final properties of fabric reinforced thermoplastics but in the case of usual resins the number of studies is low.

\section{Experimental part \\ Materials and methods}

In the attempt of understanding the tensile behavior of individual plies it is necessary to have terms to compare and that is why eight different fabrics were selected to form both plies and laminates. All these fabrics are simple type fabrics made of carbon fibers and the first intention was to find fabrics with the same specific weight. For two of the fabrics it was possible and next decision was to use simple carbon fiber fabrics with different structures (namely the number of warp and weft yarns on distance unit). Once again all the fabrics are simple type fabrics meaning that each yarn of weft is alternately below and above two consecutive yarns of warp (fig. 1.)

Analyzing images in figure 1 , one may notice that just the first three materials are fabrics while all the other five have a different aspect. The first three fabrics are denoted Carbon Fabric followed by numeric digits signifying the value of the specific weight. The forth material is realized
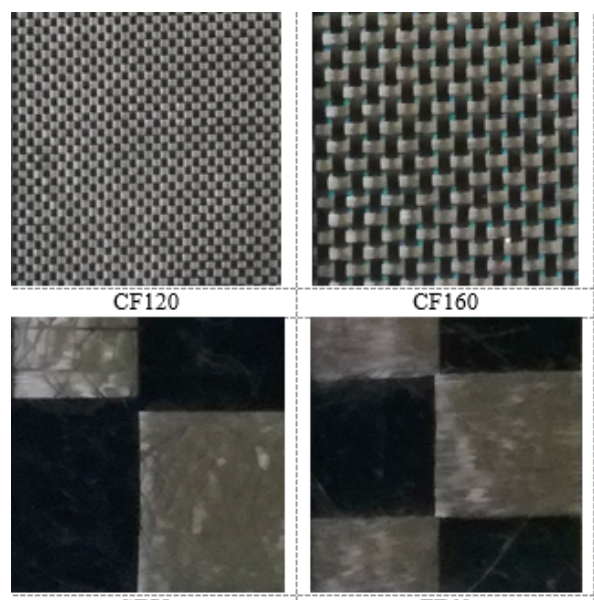

TF60
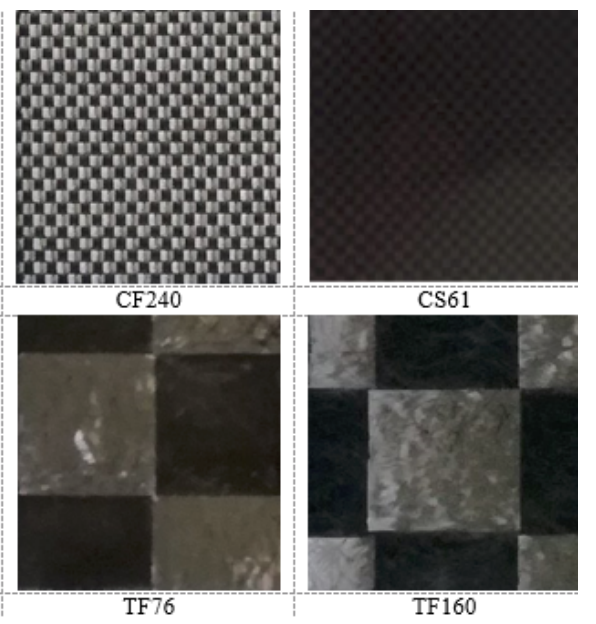

Table 1

from mat stripes of Carbon fibers while the last four materials are looking as fabrics but they are made of very thin stripes obtained by special expansion of carbon fiber tows according to the producers (http://www.textreme. com/technology/). The description of all supplied reinforcementmaterials is presented in table 1. It is obvious that, despite our intentions, there are only two reinforcement materials with the same specific weight what can be used to realize a comparison. In table 1 the next notations had been used: FT - fiber type; FS - fiber structure; WpY - number of warp yarns per length unit $\left[\mathrm{cm}^{-1}\right]$; W tY - number of weft yarns per length unit $\left[\mathrm{cm}^{-1}\right]$; SW -specific weight of material; MT - material thickness. It has to be mentioned that all the presented and studied materials are plane fabrics. With these materials plies and laminates were formed on the basis of Epiphen RE4020DE4020, an epoxy system with gel time of $45 \mathrm{~min}$ recommended both for casting and coating and we used in many studies [40-44]. Having this relative long gel time the Epiphen epoxy system is suitable to be used both for casting and for forming laminates via wetlay-up technique.

In a previous study [45] it was noticed that the tensile strength of a ply depends on the matrix thickness - any increase on matrix thickness induce a reduction of strength undelaying the fact that, during tensile tests, the ply failure occurs faster when the matrix is thick due to a shearing mechanism. At that time the tests were performed on carbon-aramid fabric and for various modified matrix obtained by adding starch, clay or carbon into the polymer.

For this study purposes the plies were formed by placing a pre-polymer imbued sheet of fabric between two pieces of glass in order to ensure the same conditions for all the materials. The ensemble was left on horizontal position and a supplementary weight was placed above. According to technical recommendations the two glass sheets were



Fig. 1. Images of fabrics

PROPERTIES OF REINFORCEMENT MATERIALS

\begin{tabular}{|c|c|c|c|c|c|c|c|c|c|c|}
\hline & \multicolumn{3}{|l|}{ FT } & \multicolumn{2}{|c|}{ FS } & $\mathrm{SW}\left[\mathrm{g} / \mathrm{m}^{2}\right]$ & \multicolumn{2}{|c|}{$\mathrm{WpY}\left[\mathrm{cm}^{-1}\right]$} & $\mathrm{Wt} Y\left[\mathrm{~cm}^{-1}\right]$ & $\mathrm{MT}[\mu \mathrm{m}]$ \\
\hline CF120 & \multicolumn{3}{|c|}{ Torayca T300 1K 67tex } & \multicolumn{2}{|c|}{$100 \% \mathrm{C}$} & 120 & \multicolumn{2}{|l|}{9} & 9 & 130 \\
\hline CF160 & \multicolumn{3}{|c|}{ AKSAKAIM A-383K 200tex } & \multicolumn{2}{|c|}{$100 \% \mathrm{C}$} & 160 & \multicolumn{2}{|l|}{4} & 4 & 180 \\
\hline $\mathrm{CF} 240$ & \multicolumn{3}{|c|}{ AKSAKATM A-38 3K 200tex } & \multicolumn{2}{|c|}{$100 \% \mathrm{C}$} & 240 & \multicolumn{2}{|l|}{6} & 6 & 290 \\
\hline $\operatorname{cs} 61$ & \multicolumn{3}{|c|}{ Tenax $\$$ HTS40 } & \multicolumn{2}{|c|}{$100 \% \mathrm{C}$} & 61 & \multicolumn{2}{|l|}{4,5} & 4,5 & 90 \\
\hline ST72 & \multicolumn{3}{|c|}{ Tenax IMS60 24K } & \multicolumn{2}{|c|}{$100 \% \mathrm{C}$} & 72 & \multicolumn{2}{|l|}{0,42} & 0,42 & 120 \\
\hline TF60 & \multicolumn{3}{|c|}{ Pyrofilm ${ }^{2} 4012 \mathrm{~K}$} & \multicolumn{2}{|c|}{$100 \% \mathrm{C}$} & 60 & \multicolumn{2}{|l|}{0,5} & 0,5 & 80 \\
\hline TF76 & \multicolumn{3}{|c|}{ Toraycaß M30SC 18K } & \multicolumn{2}{|c|}{$100 \% \mathrm{C}$} & 76 & \multicolumn{2}{|l|}{0,5} & 0,5 & 110 \\
\hline TF160 & \multicolumn{3}{|c|}{ Toraycaß T700SC 2K } & \multicolumn{2}{|c|}{$100 \% \mathrm{C}$} & 160 & \multicolumn{2}{|l|}{0,5} & 0,5 & 170 \\
\hline & & & & & $\begin{array}{r}\text { Tab } \\
\text { LIESTH }\end{array}$ & $\begin{array}{l}\text { ole } \mathbf{2} \\
\text { HICKNESS }\end{array}$ & & & & \\
\hline & & CF120 & CF1 & & $\mathrm{CF} 240$ & CS61 & ST72 & TF60 & TF76 & TF160 \\
\hline Fabric th & ness [um] & 130 & 18 & & 290 & 90 & 120 & 80 & 110 & 170 \\
\hline Ply thicl & $\mathrm{s}[\mu \mathrm{m}]$ & 180 & 27 & & 380 & 170 & 200 & 370 & 220 & 400 \\
\hline
\end{tabular}

MATERIALE PLASTICE $\bullet 6$ No. 2 * $2019 \quad$ http://www.revmaterialeplastice.ro 
removed after a week - time enough to ensure the complete polymerization. Because of the high adhesion of epoxy resin to glass surfaces these were covered with polypropylene layers in order to facilitate the sample extraction and reutilization of the large glass plates $(600 \times 600 \mathrm{~mm})$. At the end, large sheets of polymer matrix composites reinforced with one layer of fabric had been obtained, in other words, a large ply $(600 \times 600 \mathrm{~mm})$ had been obtained from each studied fabric. The method ensures also the minimal amount of polymer namely the lowest possible value of the ply thickness (table 2). It is easily to notice that just for the three reinforcement materials the thickness increases are small while for all the others (realized from stripes) there are large increases on thickness, especially in the case of CT60 material. Two mechanisms might be identified: in the case of classic fabrics (CF) a large amount of pre-polymer is absorbed inside the yarns structure namely between all the individual filaments while in the case of stripes obtained fabrics (covered with a substance designed to ensure both structure stability and matrix adhesion) a liquid film effect is blocking the pre-polymer penetration between individual filaments leading to much thicker materials.

Once extracted the materials were cut to obtain the test samples (fig. 2.) ten along the fabric warp direction, ten along the fabric weft direction, five inclined at $30^{\circ}$ relative to the warp direction, and five inclined at $45^{\circ}$ relative to the warp direction. After samples cutting they were placed into an oven to be thermally cured according to the recommendation in the technical sheet of the polymer, to achieve the best properties of the polymer. The samples dimensions were of $250 \times 25 \mathrm{~mm}$ but because of the use of regular scissors and of the material rigidity their edges are not perfect and affects, more or less, the tests results (fig. 3).

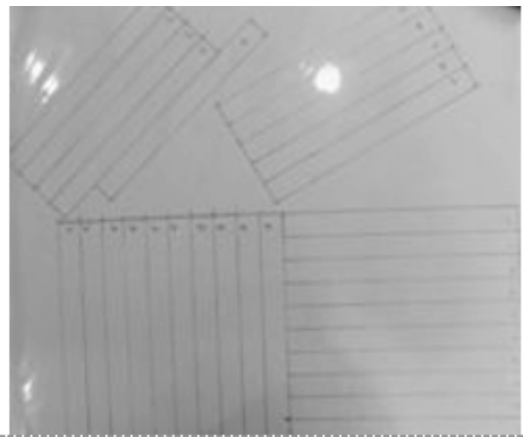

Fig. 2. Plies test samples


Fig. 3. Failure mode for axial loaded samples (regular yarns CF160 - left; spread filaments TF160 -right)
Using the same method (wet layup) pseudo-laminates had been formed with the same resin as matrix and with nine sheets of fabric as reinforcement - to denote these materials a $L$ will be placed before the fabric symbol. All the fabrics sheets were imbued with pre-polymer liquid and placed one above another on glass sheet and at the end another sheet of glass was placed above the stack of the pre-polymer imbued fabrics and the same weight (as in the case of the plies) was placed above the glass. Respecting the same procedure as in the case of plies eight laminates had been formed each one of them being composed from nine laminae made of the same fabric and with all the laminae having the same spatial orientation (all the warp yarns were parallel). It is important to notice that using the layup technique the nesting (compaction) is favored leading to materials with low thick and the fact that is hard to define a sheet of fabric as a lamina because it is not bonded between other two butkept into the matrix what polymerized at once for all de reinforcement stack. In this case the matrix seems to be like a sponge, ensuring a good loading transfer between reinforcement and matrix, of course, if the matrix-reinforcement interphase is of high quality. Generally a high quality interphase is obtained when the epoxy resins are the polymers and the carbon fiber are the reinforcement but in the case of fabrics there are some problems connected with the fact that fabrics producers are using very thin films of various polymers to maintain the regulate distribution of yarns. These polymers are claimed to ensure a very good adhesion of any polymer that could be used to form composites.

\section{Testing method}

Tensile tests were performed on an Instron Testing Machine at the Research and Development Center for Thermoset Matrix Composites. The loading speed was set at $5 \mathrm{~mm} / \mathrm{min}$ and the stop condition was set at a drop of $40 \%$ of the loading force. For each ply type ten samples were tested for axial loading (along warp and along weft) and five samples for each laminate. In the case of inclined loading ( $30^{\circ}$ and $45^{\circ}$ relative to the warp direction) five samples for each type of ply and three samples for each type of laminate were tested.

For the tests results together with the diagrams an image analysis is going to offer much information regarding the mechanical response of materials.

\section{Results and discussions}

The first observable fact is that for axial loading al the plies are failing along a warp fiber (when the loading is on the warp direction) or along a warp fiber (when the loading is along the weft direction) as it can be seen in figure 3 . In the case of inclined loadings it is obvious that a flow phenomenon is present and the flow depends on fabric thickness (on the number of individual filaments). As it can be seen in figure 3 and figure 4 there are some differences between the aspects of the failure zone especially in the case of inclined loadings - the images in figure 4 refer to the two fabrics with the same specific weight (CF160 and TF160) meaning that they have the same number of filaments on the length unit. What is to be
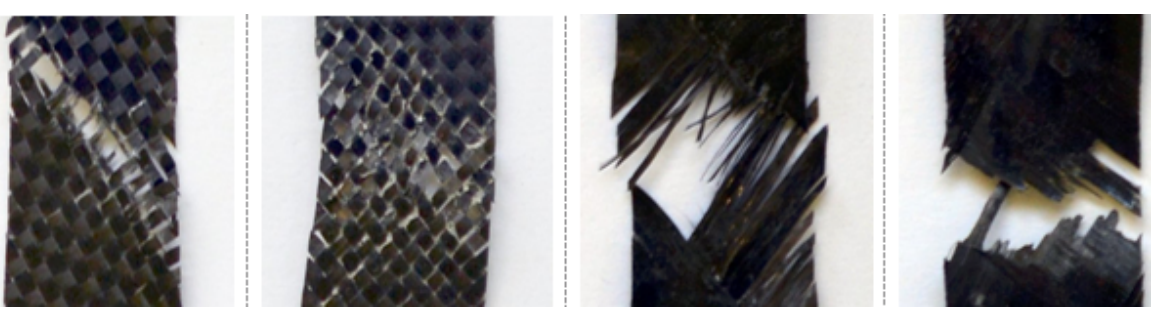

Fig. 4. Failure mode for of axis loaded samples (regular yarns -left; spread filaments -right) 
noticed is that the two fabrics were selected just for their common feature but, following the visual inspection, the conclusion is that all the regular fabrics present some short whiskers on the two sides of fractures while the fabrics obtained from spread yarns have smooth edges of fractures. In the case of inclined loading failure for all the regular fabrics the aspect of the failure zone is almost identical to the one presented for CF160 while for the other fabrics the aspect of the failure zone are alike the one presented for TF160. In this last case it might be observed that for $30^{\circ}$ orientations of loading direction there are some cut out filaments while in the case of $45^{\circ}$ there are some different wide parts of joined filaments and it is possible to notice that the aspect of the fracture zone looks like a sever delamination of the two superposed layers of spread yarns.
It is also noticeable that the CF160 samples are flowing while the TF160 samples are breaking when they are loaded at 30 or $45^{\circ}$ relative to the warp direction. The analysis showed that the flowing is proportional with the filaments density in the case of regular fabrics. Analyzing the tensile tests results it might be observed that in the case of warp direction loading the dispersion of experimental results is lower than in the case of weft direction loading and that the dispersion is higher at lower values of specific density of fabric (fig. 5). Are presented just the results for CS61 and CF240 (the lowest and the highest values of specific density for regular fabrics) but the other two materials have the same behavior. As in the case of regular fabrics, in the case of special fabrics (fig. 6.) can be noticed the same behavior of plies butthe results dispersion seems to be higher than in the case of regular fabrics reinforced plies.

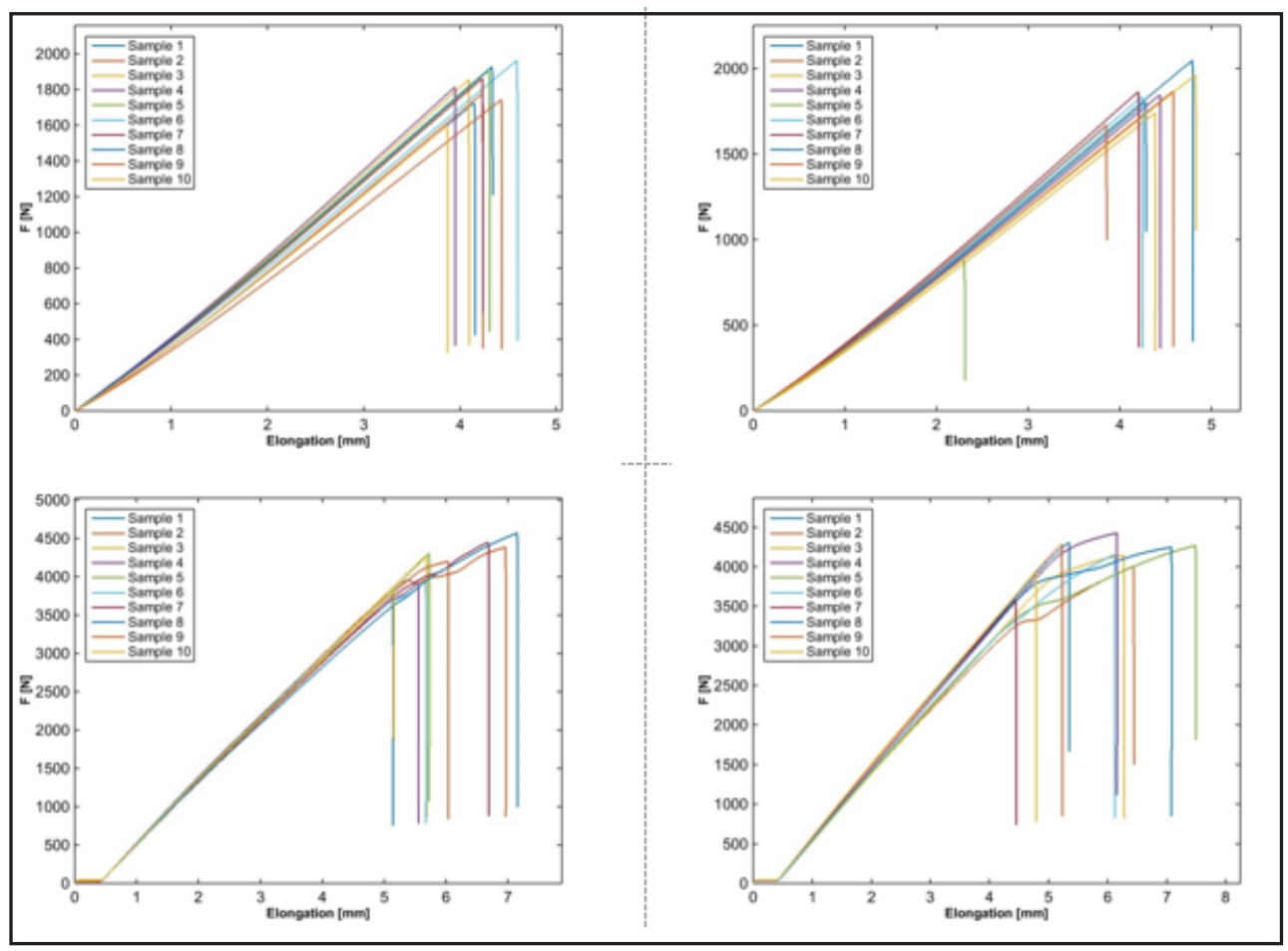

Fig. 5. Axial loading curves for regular fabrics (CS61 - up, CF240 down; warp direction - left, weft direction - right)

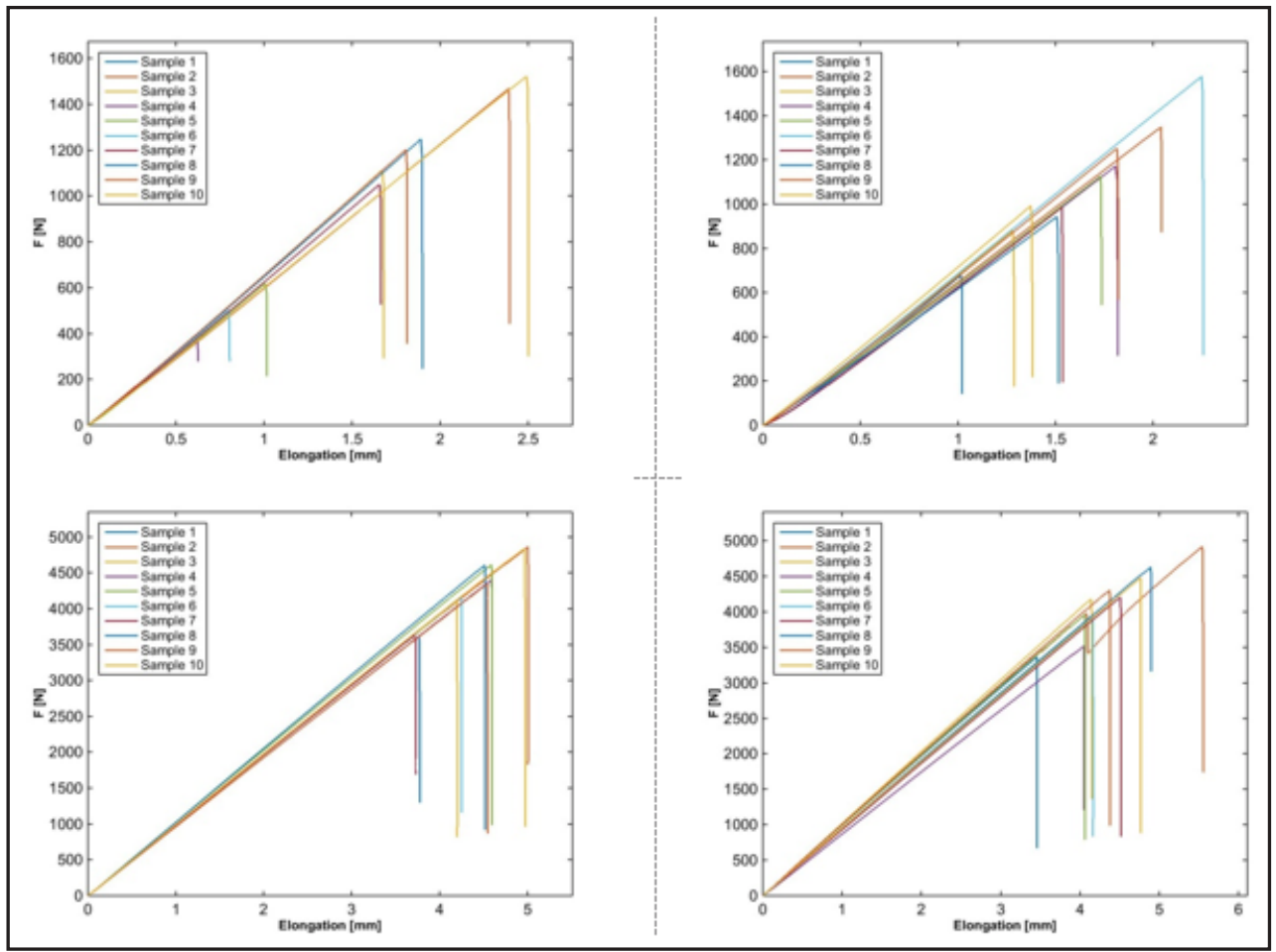

Fig. 6. Axial loading curves for special fabrics (TF60 - up, TF160 down; warp direction - left, weft direction -right) 

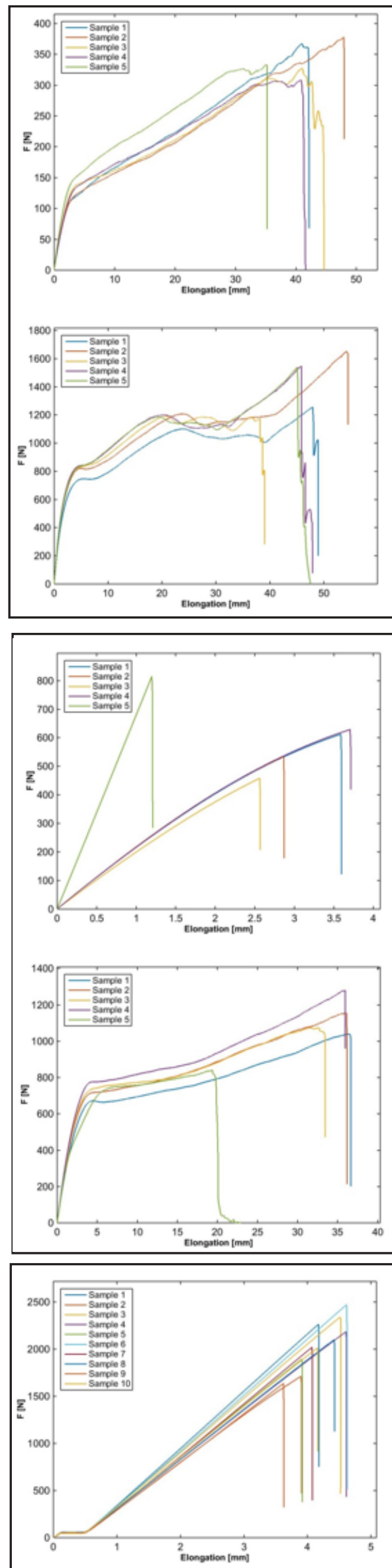
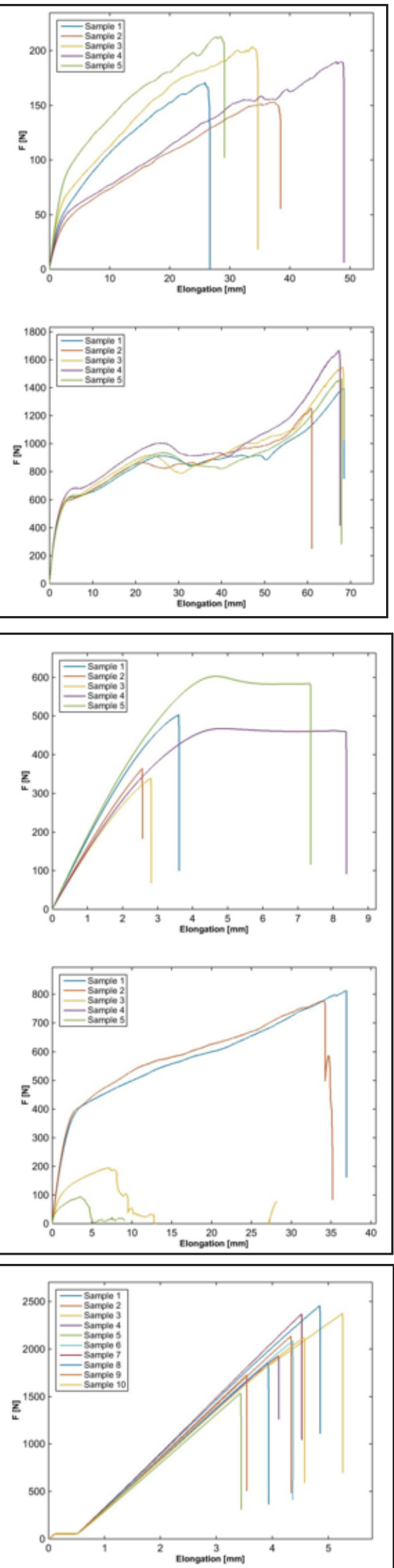

Fig. 7. Of axis loading curves for regular fabrics (CS61 -up, CF240 down; $30^{\circ}$ relative to warp directionleft, $45^{\circ}$ relative to warp direction right)
Fig. 8. Of axis loading curves for special fabrics

(TF60 -up, TF160 down; 30 relative to warp direction -left, $45^{\circ}$ relative to warp direction -right)
Fig. 9. Axial loading curves for special fabric ST72

(on warp direction -left, on weft direction -right)
For the same four fabrics the of axis loading tests results are presented in figure 7 and figure 8 and, as in the case of axial loadings, it is easily to notice that there are some differences between laminae behavior. The elongation of samples seems to be specific density dependent and, again, differences appear betw een the regular fabrics and special fabrics. The elongation, also, seems to be angle dependent being higher when of axis inclination is higher. It is noticeable the fact that in the case of inclined loadings the result dispersion is higher than in the case of axial 


\begin{tabular}{|l|c|c|c|c|}
\hline & \multicolumn{4}{|c|}{ Elastic modulus [Gpa] } \\
\hline Material & $\mathbf{0}^{\circ}$ & $\mathbf{9 0 ^ { \circ }}$ & $\mathbf{3 0 ^ { \circ }}$ & $\mathbf{4 5}^{\circ}$ \\
\hline CF120 lamina & 37.77 & 37.9 & 4.55 & 4.68 \\
\hline CF120 laminate & 23.7 & 26.86 & 7.12 & 5.74 \\
\hline CF160 lamina & 32.49 & 33.03 & 9.44 & 7.15 \\
\hline CF160 laminate & 22.38 & 20.54 & 7.58 & 5.89 \\
\hline CF240 lamina & 27.67 & 29.48 & 9.05 & 6.98 \\
\hline CF240 laminate & 20.02 & 25.26 & 9.57 & 8.14 \\
\hline CS61 lamina & 21.67 & 25.21 & 3.7 & 1.75 \\
\hline CS61 laminate & 23.74 & 22.57 & 3.24 & 2.06 \\
\hline ST72 lamina & 27.71 & 27.44 & 5.09 & 4.81 \\
\hline ST72 laminate & 18.46 & 18.28 & 4.9 & 3.26 \\
\hline TF60 & 22.51 & 21.45 & 5.07 & 4.68 \\
\hline TF76 & 25.22 & 30.08 & 4.49 & 3.5 \\
\hline TF160 lamina & 25.5 & 27.39 & 5.09 & 4.81 \\
\hline TF160 laminate & 15.67 & 15.76 & 6.36 & 5.2 \\
\hline
\end{tabular}

Table 3

ELASTIC MODULUS
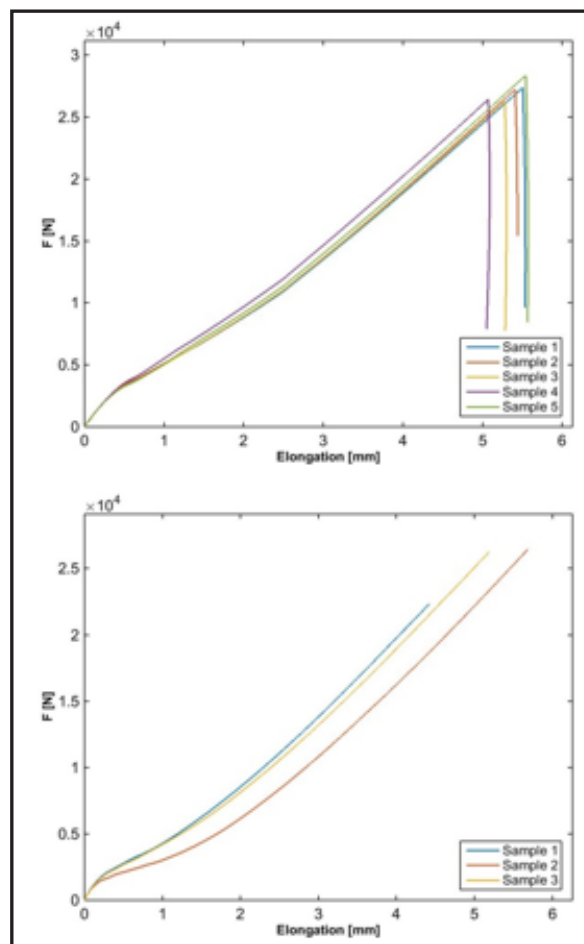
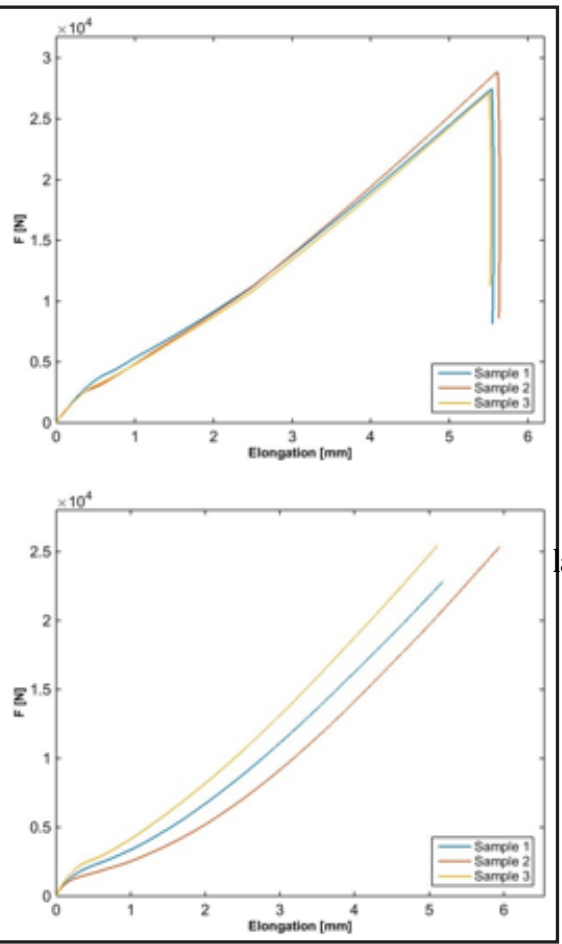

Fig. 10. Axial loading curves for aminates (CF160 -up, TF160 down; on the warp direction -left, on the weft direction -right) loadings for the same materials and the special fabrics samples are more unstable than the regular fabrics ones. Another interesting aspect is connected to the horizontal segment that appears in the case of CF240 samples and also in the case of ST72 samples (fig. 9) for both axial loadings and could be interpreted as a redistribution of fibers inside the matrix. In the case of CF240 it is, somehow, normal taking into account the fact that the yarns are thick and there exists a high probability of polymer uncovered filaments presence inside the yarn. In this case, the first zone corresponds to a composite response of the material, the second corresponds to fibers reorganization and, the third corresponds just for fibers tensile response (the same behavior was registered when other two epoxy - more brittle - systems had been used as matrix for the same fabrics).

The elastic moduli were evaluated, after statistical analysis, on the basis of $\sigma-\varepsilon$ curves for each material and for each loading direction. In table 3 the values of elastic modulus are presented with respect for warp direction loading $\left(0^{\circ}\right)$, weft direction loading $\left(90^{\circ}\right)$, and for the two of axis loadings ( 30 and $45^{\circ}$ ). It is easily to notice that, generally, the elastic modulus on the weft direction presents a higher value and that is, perhaps, due the pretension of warp yarns required in the process of fabric production.
Regarding the laminates - each one having nine sheets of reinforcement - nine plies - the tensile tests showed lower values for the elastic modulus than in the case of tensile tests of laminae - as it might be noticed in table 3. This tendency might be explained based on three reasons: first one is connected to the forming method (lay-up) that is allowing the natural arrangement of fabric layers leading to the nesting effect, the second takes into account the existence of polymer pockets with effects on loading transfer and, the third, is taking into account the fact that due again to the forming technique there is possible that the polymer do not penetrate to the inner part of the yarns of fibers all of them with consequences on the linear response of material as can be seen in figure 10 and figure 11. Generally the special fabrics reinforced laminates have been more fragile such as some of the samples had failed earlier (at the grips level) making impossible their analysis. Also there are some differences regarding the effects of the loading direction - on one hand for axial loaded samples the fracture direction is perpendicular on the loading direction (independent on the type of fabric) - figure 12 and, on the other hand, the of axis loading leads to different responses - especially filaments removed from the matrix and with remaining deformations as it can be noticed in figure 13. 


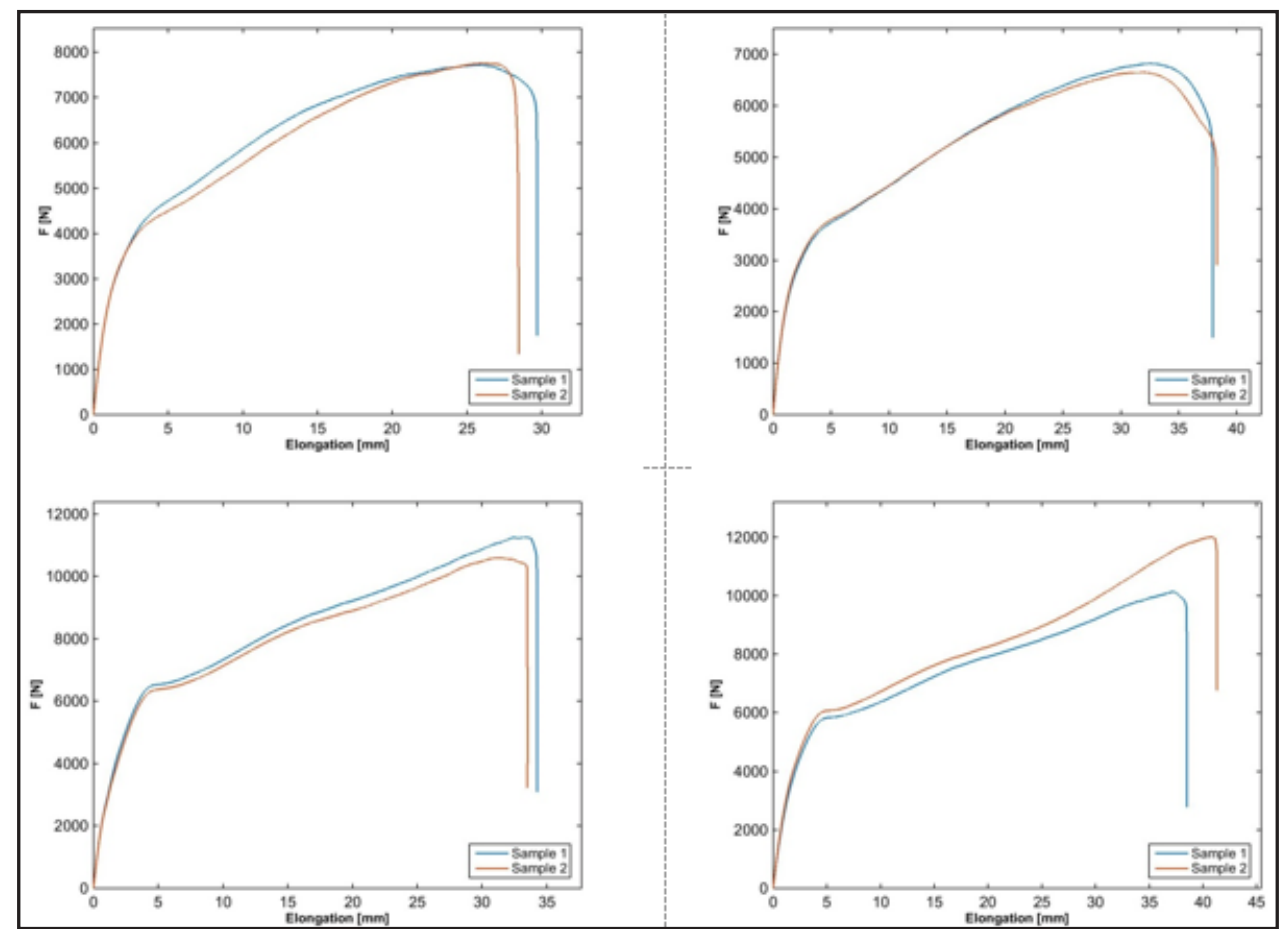

Fig. 11. Of axis loading curves for laminates (CF160 -up, TF160 down; $30^{\circ}$ relative to warp direction -left, $45^{\circ}$ relative to warp direction -right)

Fig. 12. Effects of axial loading on laminates

(CF160 - left, TF160 - right)
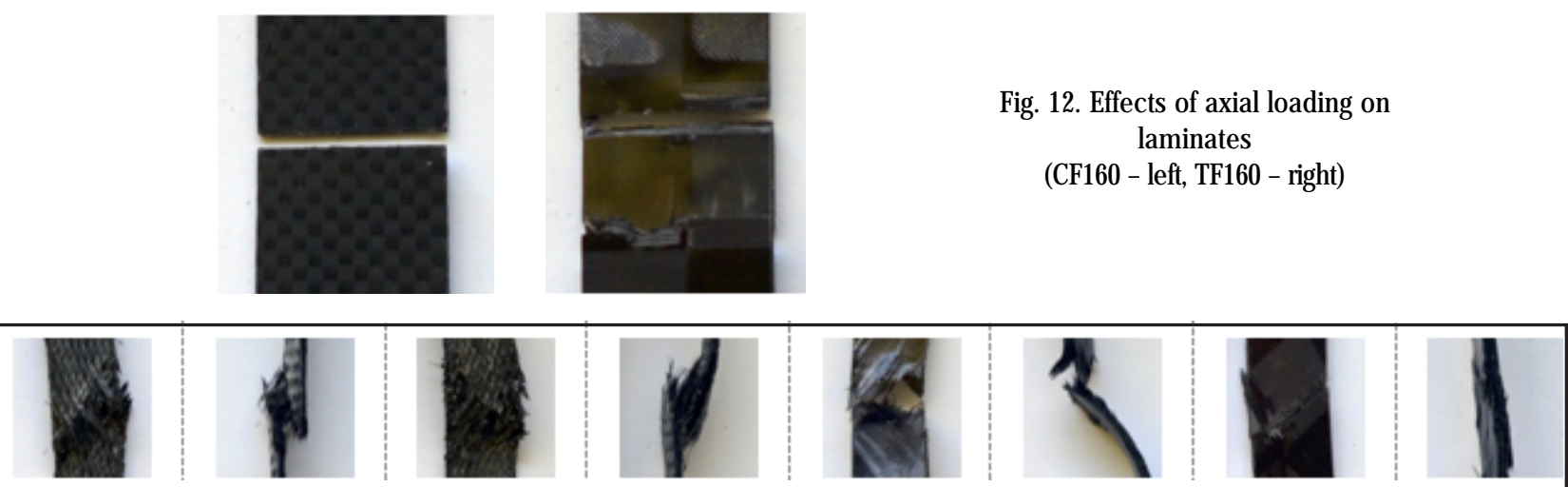

Fig. 13. Effects of inclined loading on laminates from left to right CF160 $30^{\circ}$-face; CF160 30 -profile; CF160 $45^{\circ}$-face; CF160 $45^{\circ}$-profile;TF160 $30^{\circ}$ face; TF160 $30^{\circ}$-profile; TF160 $45^{\circ}$-face; TF160 $45^{\circ}$-profile.

\section{Conclusions}

Eight different fabrics had been used to form laminae and, six of them to form laminate composites with epoxy resin matrix. The study was developed to qualitatively analyze the effect of the type of fabric and the specific weight of fabrics on the tensile behavior of fabric reinforced materials. All the materials had been formed using the same technique and in the same conditions such as they can be considered identical from these two points of view.

Differences had been emphasized between the laminae behavior when they are axially loaded (along the warp or along the weft) with effects on the elastic modulus value (higher for loading on the weft direction than in the case of loading on the warp direction) due to the necessary pretension of the warp yarns. In the case of 30 and $45^{\circ}$ loadings directions (relative to warp direction) the regular fabrics reinforced materials are flowing (the elongation being dependent on the specific weight of the fabric) while special fabrics reinforced laminae present an aspect of delamination.

The laminates show lower values of elastic modulus, relative to correspondent laminae, because of nesting effect induced by the forming technique, polymer pockets and the fact that probably the polymer does not reach the inner part of the fibers yarns. Also, in the case of laminates the axial loaded samples are breaking on a direction perpendicular to the loading direction while in the case of inclined loaded samples the flowing is observed and the deformations of the twisted samples is permanent. Also for laminates there are significant differences on the failure zones aspect for the regular fabrics and special fabrics reinforced materials.

Of course, some of the differences could be explained by fabrics properties reasons, taking into account the fact that the fabrics are made of different types of fibers but, for this study, these variables were not considered. An extension of this study have to be developed for the case of fabrics made of the same type of fibers but with different specific weight.

\section{References}

1. VALENCA, S. L., GRIZA, S., GOMES DE OLIVEIRA, V., SUSSUCHI, E. M., CARVALHO DA CUNHA, F. G., Composites: Part B, 70, 2015, pp. 1-8. http:/ /dx.doi.org/10.1016/j.compositesb.2014.09.040

2. TRIKI, E., ZOUARI, B., DAMMAK, F., Engineering Fracture Mechanics, 159, 2016, pp. 63-78, http://dx.doi.org/10.1016/j.engfracmech. 2016.03.025

3. MALLIHARACHCHI, H. M. Y. C., Thin-Walled Structures, 135, 2019, pp. 297-305, https:// doi.org/10.1016/j.tws.2018.11.016

4. BEHERA, B. K., DASH, B. P., Materials and Design, 67, 2015, pp. 261271, http://dx. Doi.org/10.1016/j.matdes.2014.11.020

5. SALEH, M. N., LUBINEAU, G., POTLURI, P., WITHERS, P. J., SOUTIS,

C., Composites Structures, 156, 2016, pp. 115-124, http://dx.doi.org/ 10.1016/j.compstruct.2016.01.021 
6. GREEN, S. D., MATVEEV, M. Y., LONG, A. C., IVANOV, D., HALLETT, S. R., Composite Structures, 118, 2014, pp. 284-293, http://dx.doi.org/ 10.1016/j.compstruct.2014.07.005.

7. KARAHAN, M., LOMOV, S. V., BOGDANOVICH, A. E., MUNGALOV, D., VERPOEST, I., Composites: PartA, 41, 2010, pp.1301-1311, doi:10.1016/ j.compositesa.2010.05.014.

8. DAI, S., CUNNINGHAM, P. R., MARSHALL, S., SILVA, C., Composites: Part A, 69, 2015, pp. 195-207, http://dx.doi.org/10.1016/ j.compositesa.2014.11.012.

9. ZHOU, Y., LU, Z., YANG, Z., Composites: Part B, 47, 2013, pp. 220229, http://dx.doi.org/10. 1016/j.compositesb.2012.10.026.

10. WANG, L., WU, J., CHEN, G., ZHENG, C., LI, B., JOSHI, S. C., Composites Structure, 178, 2017, pp. 395-405, http://dx.doi.org/10.1016/ j.compstruct.2017.07.023.

11. MACHADO, M., FISCHLSCHWEIGER, M., MAJOR, Z., Composites: Part A, 80, 2016, pp. 194-203, http://dx.doi.org/10.1016/ j.compositesa.2015.10.028.

12. MADRA, A., BREITKOPF, P., RAGHAVAN, B., TROCHU, F., Comptes Rendus Mecanique, 346, 2018, pp. 532-538, https://doi.org/10.1016/ j.crme.2018.04.008.

13. NAIR, R. G., SUNDARARAJAN, T., GURUPRASAD, P. J., Composite Structures, 202, 2018, pp. 261-274, https://doi.org/10.1016/ j.compstruct.2018.01.072.

14. KOOHBOR, B., RAVINDRAN, S., KIDANE, A., Optics and Lasers in Engineering, 90, 2017, pp. 59-71, http://dx.doi.org/10.1016/ j.optlaseng.2016.10.001.

15. WANG, L., ZHAO, B., WU, J., CHEN, C., ZHOU, K., International J ournal of Mechanical Sciences, 141, 2018, pp. 157-167, https://doi.org/ 10.1016/j.jijmecsci.2018.03.030.

16. MAHADIK, Y., HALLETT, S. R., Composites: Part A, 42, 2011, pp. 1592-1600, doi:10.1016/ j.compositesa.2011.07.006

17. KHARRATZADECH, M., SHOKRIECH, M. M., SALAMAT-TALAB, M., Theoretical and Applied Fracture Mechanics, 98, 2018, pp. 1-12, https:/ /doi.org/10.1016/j.tafmec.2018.09.006.

18. AKMAR ABU BAKAR, I., KRAMER, O., BORDAS, S., RABCZUK, T., Composite Structures, 100, 2013, 575-591, http://dx.doi.org/10.1016/ j.compstruct.2012.12.043.

19. LIU, X., ROUF, K., PENG, B., YU, W., Composite Structures, 171 2017, pp. 252-262, http://dx. Doi.org/10.1016/j.compstruct.2017.03.029. 20. KUBO, G., MATSUDA, T., SATO, Y., International J ournal of Mechanical Studies, 146-147, 2018, pp. 497-506, https://doi.org/10.1016/ j.ijmecsci.2018.01.007.

21. YANG, B., WANG, S., WANG, Y., Applied Composite Materials, 25, 2018, pp. 1237-1253, https://doi.org/10.1007/s10443-018-9699-8.

22. OLAVE, M., VARA, I., USABIAGA, H., ARETXABALETA, L., LOMOV, S. V., VANDEPITTE, D., Composite structures, 133, 2015, pp. 226-234, http://dx.doi.org/10.1016/j. compstruct.2015.07.073.

23. OLAVE, M., VARA, I., USABIAGA, H., ARETXABALETA, L., LOMOV, S. V., VANDEPITTE, D., Composites: Part A, 74, 2015, pp. 166-173, http:/ /dx.doi.org/10.1016/j. compositesa.2015.03.017.

24. OLAVE, M., VARA, I., USABIAGA, H., ARETXABALETA, L., LOMOV, S. V., VANDEPITTE, D., Composites: Part A, 74, 2015, pp. 174-181, http:/ /dx.doi.org/10.1016/j. compositesa.2015.03.020.
25. XIONG, J. J., SHENOI, R. A., CHENG, X., Composites: Part B, 40, 2009, pp. 776-783, doi:10.1016/j.compositesb.2009.06.004.

26. ZHOU, L., CHEN, M. W., LIU, C., WU, H., Composite Structures, 204, 2018, pp. 536-547, https://doi.org/10.1016/j.compstruct.2018.07.128. 27. ROMELT, P., CUNNINGHAM, P. R., Composite Structures, 94, 2012, pp. 977-986, doi:10.1016/j.compstruct.2011.10.024.

28. OBERT, E., DAGHIA, F., LADEVEZE, P., BALLERE, L., Composite Structures, 117, 2014, pp. 212-221, http://dx.doi.org/10.1016/ j.compstruct.2014.06.035.

29. UDHAYARAMAN, R., MULAY, S. S., Mechanics of Materials, 112, 2017, pp. 172-192, http://dx.doi.org/10.1016/j.mechmat.2017.06.007.

30. CARPENTER, A. J ., CHOCRON, S., ANDERSON, C. E. J r., International Journal of Impact Engineering, 120, 2018, pp. 31-45, https://doi.org/ 10.1016/j.jijimpeng.2018.05.005.

31. PANT, S., LALIBERTE, J., MARTINEZ, M., ROCHA, B., Composite Structures, 111, 2014, pp. 566-579, http://dx.doi.org/10.1016/ j.compstruct.2014.01.034.

32. ONG, W. H., RAJIC, N., CHIU, W. K., ROSALIE, C., Composite Structures, 141, 2016, pp. 24-31, http://dx.doi.org/10.1016/ j.compstruct.2015.12.017.

33. PANT, S., LALIBERTE, J., MARTINEZ, M., ROCHA, B., ANCRUM, D., Composite Structures, 124, 2015, pp. 236-252, http://dx.doi.org/10.1016/ j.compstruct.2015.01.017.

34. ZHU, C., ZHU, P., LIU, Z., Composite Structures, 207, 2019, pp. 684700, https://doi.org/ 10.1016/j.compstruct.2018.09.089.

35. XU, W., GUO, Z. Z., YU, Y., XIONG, J., GAO, Y., Composite Structures, 206, 2018, pp. 713-721, https://doi.org/10.1016/ j.compstruct.2018.08.050.

36. LIU, H., FALZON, B. G., TAN, W., Composites: Part B, 136, 2018, pp. 101-118, http://dx.doi. Org/10.1016/j.compositesb.2017.10.016.

37. FANTERIA, D., LAZZERI, L., PANETTIERI, E., MARIANI, U., RIGAMONTI, M., Composites Science and Technology, 142, 2017, pp. 20-29, http:// dx.doi.org/10.1016/j.compscitech.2017.01.028.

38. WAREN, K. C., LOPEZ-ANIDO, R. A., GOERING, J ., Composites: PartA, 73, 2015, pp. 242-259, http://dx.doi.org/10.1016/j.compositesa. 2015.03.011.

39. KOOHBOR, B., RAVINDRAN, S., KIDANE, A., Composite Structures, 194, 2018, pp. 328-334, https://doi.org/10.1016/j.compstruct.2018.04.016. 40. BRIA, V., CIRCIUMARU, A., BIRSAN, I.-G., Mat. Plast., 48, 2011, p.189-194,

41. BRIA, V., MUNTENTA, C., GRAUR, I., Mat. Plast., 55, no. 3, 2018, p. 295-298

42. BUNEA, M., BOSOANCA, R., COJAN, A., BIRSAN, I.-G., Mat. Plast., 55, no. 3, 2018, p. 269-273

43. MUNTENITA, C., BRIA, V., ENI, C., CIRCIUMARU, A., GRAUR, I., Mat. Plast., 53, 2016, p. 509-511

44. MIHU, G., MIHALACHE, I., BODOR, M., MIRCEA, O., GRAUR, I., Mat. Plast., 53, 2016, p. 298-303

45. UNGUREANU, V., BRIA, V., ROMAN, I., BIRSAN, I.-G., CIRCIUMARU, A., Mechanical analysis of fabric reinforced epoxy laminae, International Conference POLYMER COMPOSITES 2011, Plzni, Czech Republic, pp. 127-130, ISBN 978-80-7043-984-5.

$\overline{\text { Manuscript received: } 23.03 .2019}$ 